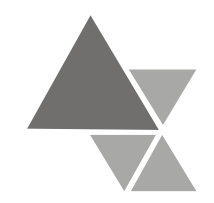

\title{
A Alimentação das Famílias do Centro-Oeste Brasileiro: Subsídios para Ações de Segurança Alimentar e Nutricional
}

\author{
Carla Cristina Enes ${ }^{1}$, Marina Vieira da Silva ${ }^{2}$
}

O objetivo da pesquisa foi analisar a disponibilidade domiciliar de energia, colesterol e fibras, a participação relativa dos macronutrientes no Valor Energético Total - VET e a contribuição dos grupos de alimentos na energia disponível para as famílias residentes na Região Centro-Oeste do País. Utilizou-se, para a elaboração das análises, os microdados da Pesquisa de Orçamentos Familiares - POF, realizada pelo Instituto Brasileiro de Geografia e Estatística - IBGE, no período de 2002 a 2003. Para as análises nutricionais, utilizou-se o software Virtual Nutri. Constatou-se uma relação inversa entre a participação dos carboidratos no VET e a renda. A mesma tendência foi observada para os lipídios e colesterol. A disponibilidade de fibras revelou-se muito aquém dos valores preconizados para a totalidade dos estratos de renda. Quanto à participação dos distintos grupos de alimentos no VET, destaca-se a reduzida contribuição energética das frutas e hortaliças para os moradores das áreas urbanas e rurais. A contribuição dos doces, açúcares e refrigerantes foi identificada como excessiva no VET disponível para as famílias de ambos os estratos geográficos.

Palavras-chave: disponibilidade alimentar, consumo de frutas e verduras, renda familiar, segurança alimentar, pof

\section{Household food consumption in the Mid-West Region of Brazil: a contribution to public food policies}

The aim of this study was to analyze the food availability at the household level in terms energy, cholesterol and fiber, the relative participation of macronutrients in the Total Energy Value (TEV) and the contribution of the different food groups to the energy available in the households of the Brazilian Mid-West Region. For such purpose, the 2002/03 micro-data of the Family Budget Survey - POF obtained by the Brazilian Institute of Geography and Statistics -IBGE- were used. The nutritional analyses were carried out utilizing the Virtual Nutri software. An inverse relationship between the participation of carbohydrates in the TEV and family income was observed. The same tendency was detected for lipids and cholesterol. The availability of fiber was far less than the values recommended irrespective of the income bracket. With regard to the participation of the different food groups in the TEV, the contribution of fruits, greens and vegetables of urban and rural residents to the total energy availability was remarkably low. An undesirably excessive contribution of sweets, sugar and soft drinks to the available TEV was identified for families of both geographic strata.

Keywords: food availability, diet composition, family income, food security, fruits and vegetables, pof

\footnotetext{
${ }^{1}$ Departamento de Nutrição da Faculdade de Saúde Pública da USP.

${ }^{2}$ Departamento de Agroindústria, Alimentos e Nutrição da Escola Superior de Agricultura "Luiz de Queiroz" ESALQ/USP.
} 


\section{Introdução}

Os processos demográficos, tecnológicos, econômicos e ambientais, ocorridos em todo o mundo, exerceram forte efeito na disponibilidade de alimentos. Uma grande disparidade surgiu entre os padrões de acesso e consumo de alimentos em vários grupos populacionais, entre regiões e países e, particularmente, entre as áreas urbanas e rurais $^{[1]}$.

O perfil alimentar adotado no meio rural, a partir dos anos 90, passou a apresentar características distintas daquelas freqüentemente observadas. Entre outros fatores, os indivíduos passaram a substituir parte de seus hábitos alimentares por aqueles adotados pela população do meio urbano.

Publicação da World Health Organization (WHO) ${ }^{[2]}$ chama a atenção para as mudanças ocorridas na economia alimentar mundial, que têm sido apontadas como responsáveis pelo aumento do consumo de dietas de elevada densidade energética, fontes de gorduras, especialmente saturadas, redução do consumo de carboidratos complexos e fibras, além da diminuição do consumo de frutas e hortaliças.

Os resultados identificados por intermédio das análises das Pesquisas de Orçamentos Familiares - POF's, realizadas desde a década de 70 , revelam uma tendência de incremento na aquisição de produtos industrializados e redução de alimentos in natura por parte das famílias ${ }^{[3]}$.

Resultados obtidos por Barretto e Cyrillo $^{[4]}$, por meio de uma pesquisa de identificação de estruturas de consumo alimentar, realizada entre os anos de 1990 a 1996, no município de São Paulo, corroboram dados e análises implementadas mais recentemente. Os autores verificaram uma redução de 6 a 7 pontos percentuais da parcela dos gastos com os produtos semi-elaborados. A proporção dos gastos com os alimentos industrializados teve um aumento que variou de 8 a 10 pontos percentuais. Foi constatado também um decréscimo (entre os anos de
1990-1992 e 1995-1996) de, aproximadamente, $35 \%$ na proporção do orçamento despendido com a aquisição de frutas, legumes e verduras.

$\mathrm{O}$ mesmo estudo mostrou ainda que, à medida que os rendimentos das famílias se elevam, os produtos semi-elaborados têm menor participação nas despesas domiciliares, havendo, por outro lado, um aumento na percentagem dos gastos com produtos industrializados e in natura.

Claro $^{[5]}$, tendo por base as informações compiladas pela POF, realizada no município de São Paulo (1998/1999), por meio da Fundação Instituto de Pesquisas Econômicas, identificou a influência dos rendimentos e preços dos alimentos sobre o nível da disponibilidade de frutas e hortaliças nos domicílios.

Cabe destacar, também, que diversas pesquisas implementadas em países desenvolvidos revelam, por exemplo, que dietas com menor densidade energética ou que envolvem substancial conteúdo de frutas e hortaliças tendem a ter maior custo do que as demais ${ }^{[6]}$.

Entre vários outros aspectos, a mudança de hábitos alimentares, com o estabelecimento de padrões considerados inadequados, tem produzido novos agravos à saúde humana. Como conseqüência direta, há uma maior incidência das doenças crônicas não-transmissíveis como obesidade, diabetes melito tipo 2, câncer, doenças cardiovasculares, dentre outras.

Vários autores enfatizam a escassez de estudos com representatividade nacional que analisem o impacto exercido pela renda das famílias e a influência dos preços dos alimentos sobre o padrão alimentar ${ }^{[4,7]^{3}}$.

A opção pela análise dos dados da Região Centro-Oeste deve-se ao número limitado de estudos disponíveis envolvendo esta região, já que a maioria dos trabalhos prioriza os grupamentos familiares residentes nas regiões Sudeste e Nordeste do país.

Tendo em vista a reconhecida influência de inúmeros fatores sobre o perfil 
dietético da população e os efeitos negativos gerados pela adoção de hábitos alimentares inadequados, o presente artigo teve como objetivo analisar a disponibilidade domiciliar de energia, colesterol e fibras, a participação relativa dos macronutrientes no Valor Energético Total - VET e a contribuição dos grupos de alimentos na energia disponível para as famílias residentes na Região CentroOeste do Brasil.

\section{Metodologia}

Foram utilizadas como base de dados as informações obtidas pela Pesquisa de Orçamentos Familiares - POF 2002/2003, realizada pelo IBGE. Os dados foram coletados em todo o território nacional, durante o período de um ano $\left(1^{\circ}\right.$ de julho de 2002 a 30 de junho de 2003).

As informações referentes à aquisição de alimentos foram obtidas por meio de um registro diário, durante sete dias consecutivos, com descrição pormenorizada (quantidade, unidade de medida, peso, volume) de cada produto adquirido para consumo.

Para a construção do banco de dados, foi elaborado, inicialmente, a partir dos microdados da POF $(\text { IBGE })^{[8]}$, um agrupamento de alimentos, considerando a totalidade que compunha o banco original (5.442 citações). Para viabilizar os cálculos de disponibilidade de energia e nutrientes, os alimentos foram agrupados levando-se em conta a semelhança entre a composição nutricional. Posteriormente, foram calculadas as porções comestíveis dos alimentos (carnes, legumes, frutas e hortaliças), utilizando-se os índices de conversão indicados para cada produto $^{[9,10]}$.

Os alimentos e suas respectivas quantidades foram cadastrados no software Virtual Nutri - Sistema de Análise Nutricional (versão 6.0) ${ }^{[11]}$, com vistas à viabilização do cálculo do conteúdo de energia e nutrientes. É importante registrar que foi realizada uma revisão das informações relativas à composição nutricional dos alimentos integrantes do banco original do referido software, visando uma atualização dos dados e possíveis correções.

Para os alimentos cuja composição nutricional não integrava o acervo original do referido software, foram obtidos dados registrados em diversas tabelas de composição de alimentos $^{[12,13,14]}$ e os valores foram incorporados ao arquivo original do programa. Em alguns casos, as informações (registradas nos rótulos dos alimentos) fornecidas pela empresa serviram como referência.

Para a obtenção do consumo domiciliar per capita diário, efetuou-se a divisão dos valores de consumo (anual) de cada alimento por 365 dias e multiplicou-se os valores encontrados por 1.000 , para a obtenção dos dados de consumo em gramas. A partir destes valores, foram calculadas as disponibilidades médias diárias de energia e nutrientes para as famílias da Região CentroOeste do Brasil.

Foram elaboradas, no presente estudo, análises referentes ao conteúdo disponível de energia e à contribuição relativa dos macronutrientes (carboidratos, proteínas e lipídios) no VET de acordo com o rendimento mensal familiar. Analisou-se ainda a contribuição dos diferentes grupos de alimentos na energia disponível no âmbito domiciliar. Tanto no caso dos grupos de alimentos quanto no caso dos macronutrientes, a participação relativa na disponibilidade alimentar foi expressa a partir da proporção de calorias que o alimento fornecia em relação ao total de energia disponível para consumo no domicílio. Os grupos de alimentos foram definidos conforme critérios de semelhança quanto à composição nutricional dos alimentos.

Foram distinguidos dezessete grupos de alimentos, a saber: cereais e derivados; raízes, tubérculos e derivados; carnes e embutidos; leguminosas; leite e derivados; ovos; hortaliças; frutas; açúcares e doces; óleos e gorduras vegetais; banha, toucinho, maionese e creme de leite; oleaginosas; refrigerantes; bebidas não-alcoólicas; bebidas alcoólicas; preparações prontas para o consumo e condimentos.

Para a avaliação da participação relativa dos macronutrientes no VET, foram 
adotados os valores recomendados pelo Institute of Medicine ${ }^{[15]}$, que correspondem aos seguintes intervalos: 45 a $65 \%$ provenientes dos carboidratos, 10 a 35\% de proteínas e 20 a $35 \%$ de lipídios.

Adotou-se como parâmetro, para a avaliação da disponibilidade de energia, o valor de $2.300 \mathrm{kcal}$, estimado pela Food and Agriculture Organization ${ }^{[16]}$ para a população brasileira.

\section{Resultados e Discussão}

\section{Disponibilidade de macronutrientes e renda familiar}

Os dados apresentados na Tabela 1 mostram a nítida tendência de aumento da disponibilidade de energia, conforme ocorre o crescimento dos rendimentos, principalmente até o intervalo delimitado pelos valores entre 5,1 e 6,0 s.m. É importante registrar que as famílias com menores rendimentos (até 2 s.m.) dispõem de menor conteúdo (médio) de energia (1.540,7 kcal).

Na seqüência, observa-se propensão de decréscimo para depois ocorrer novo aumento da disponibilidade de energia nos domicílios das famílias com rendimentos entre 15,1 e 20,0 s.m. Tal resultado pode ser explicado, em parte, pela inclinação de maior frequiência de consumo de alimentos fora do domicílio, conforme ocorre o crescimento dos rendimentos ${ }^{[17]}$. Ressalta-se que para nenhum dos grupamentos analisados foi observado o valor (médio) de energia freqüentemente preconizado para um adulto $(2.300 \mathrm{kcal} / \mathrm{dia})$.

De acordo com Silveira ${ }^{[17]}$, estima-se que nos grandes centros urbanos como, por exemplo, São Paulo, quase metade da energia total disponível, para a população com rendimento mensal superior a trinta salários mínimos, é originária de refeições fora do domicílio. Em contrapartida, calcula-se que entre as famílias cujos rendimentos não ultrapassam dois salários mínimos, a proporção atinja 21\%

Tabela 1. Disponibilidade de energia e participação dos macronutrientes no VET diário dos domicílios das famílias da Região Centro-Oeste do Brasil, de acordo com os estratos de rendimentos mensais. 2002-2003.

\begin{tabular}{cccccccc}
\hline $\begin{array}{c}\text { Estratos de } \\
\text { Rendimentos }\end{array}$ & Energia & \multicolumn{2}{c}{ Carboidratos } & \multicolumn{2}{c}{ Proteínas } & \multicolumn{2}{c}{ Lipídios } \\
\cline { 3 - 7 }$($ em salários & & & & & & & \\
mínimos $)$ & $(\mathrm{kcal})$ & $(\mathrm{g})$ & $(\%)$ & $(\mathrm{g})$ & $(\%)$ & $(\mathrm{g})$ & $(\%)$ \\
\hline$\leq 2,0$ & & & & & & & \\
2,1 a 3,0 & 1540,7 & 236,1 & 61,3 & 35,9 & 9,3 & 50,3 & 29,4 \\
3,1 a 5,0 & 1645,9 & 250,8 & 61,0 & 40,1 & 9,7 & 53,8 & 29,4 \\
5,1 a 6,0 & 1662,4 & 249,3 & 60,0 & 41,7 & 10,0 & 56,2 & 30,4 \\
6,1 a 8,0 & 1894,6 & 280,2 & 59,2 & 48,8 & 10,3 & 64,8 & 30,8 \\
8,1 a 10,0 & 1876,1 & 277,7 & 59,2 & 49,5 & 10,6 & 63,2 & 30,3 \\
10,1 a 15,0 & 1730,4 & 260,5 & 60,2 & 46,3 & 10,7 & 55,7 & 29,0 \\
15,1 a 20,0 & 1517,8 & 217,2 & 57,2 & 44,1 & 11,6 & 52,4 & 31,1 \\
20,1 a 30,0 & 1559,2 & 210,7 & 54,0 & 44,2 & 11,3 & 60,0 & 34,6 \\
$>$ 30,1 & 1722,5 & 250,3 & 58,1 & 46,4 & 10,8 & 59,6 & 31,1 \\
& 1740,6 & 238,1 & 54,7 & 53,8 & 12,4 & 62,6 & 32,4 \\
\hline
\end{tabular}


Há reconhecimento também que o cenário urbano atual estimula, demasiadamente, o consumo de alimentos calóricos, ao mesmo tempo em que restringe as oportunidades ou estímulos para a adoção de práticas de atividades física.

A composição do conjunto dos alimentos, referente aos macronutrientes, evidencia uma tendência de redução da participação dos carboidratos no VET, conforme há um aumento dos rendimentos familiares. Observa-se que a menor contribuição (54\%) desse macronutriente para a energia disponível foi identificada para as famílias pertencentes ao estrato de 15,1 a 20 s.m. Ao contrário, os carboidratos tiveram uma participação mais expressiva $(61,3 \%$ do VET) entre a população mais pobre (renda de até 2 s.m.).

Bleil $^{[18]}$, analisando dados da POF obtidos junto às famílias da Região Sul do Brasil, em meados da década de 90, encontrou resultados semelhantes, ou seja, a participação relativa do carboidrato no VET foi mais expressiva entre as famílias mais pobres (até 2 s.m.).

Esses resultados podem ser decorrentes do preço relativamente inferior dos alimentos de origem vegetal (ricos em carboidratos), como é o caso dos cereais, raízes e tubérculos. Tal situação possibilita um maior acesso das famílias pertencentes a camadas mais pobres a esses alimentos e, por conseqüência, maior conteúdo de energia disponível.

Salienta-se também que, embora tenha sido observada uma variação na participação dos carboidratos na energia total disponível para os distintos grupos de rendimentos e para a totalidade das famílias, os resultados revelaram que a proporção de energia oriunda desse nutriente integra o intervalo preconizado (45-65\%).

No tocante à quantidade de proteínas disponíveis nos domicílios, o comportamento é semelhante àquele observado para $o$ conteúdo energético. Entre as famílias de menor poder aquisitivo, a participação em relação ao VET mostrou-se inferior ao intervalo recomendado (10-35\%). Por outro lado, a proporção mais expressiva da proteína na energia total disponível foi identificada nos domicílios das famílias de maior poder aquisitivo $(12,4 \%)$, o que poderia ser explicado, em parte, pelo custo mais elevado dos alimentos com expressivo teor protéico (carnes, leite e derivados).

No caso dos lipídios, nota-se que o limite máximo de $35 \%$ da energia total não foi excedido para nenhum grupamento. Sendo assim, para a totalidade das famílias analisadas, a proporção de energia proveniente das gorduras revelou-se em conformidade com o intervalo recomendado (20 a 35\%).

Embora o teor lipídico não tenha excedido os limites recomendados, é interessante frisar que as análises implementadas nesta pesquisa envolveram apenas a disponibilidade de alimentos nos domicílios, sendo possível que a proporção de energia originária desse macronutriente fosse ainda maior caso se estimasse o conteúdo total obtido por meio da alimentação fora do domicílio, especialmente quando se considera a tendência da maior oferta de alimentos comercializados por lanchonetes, fast-food, bares e restaurantes, que apresentam um maior conteúdo de gordura.

Fietz ${ }^{[19]}$ analisando a dieta de moradores (assentados) da zona rural do Estado de Mato-Grosso do Sul (Região Centro-Oeste), identificou que a proporção média de energia ingerida, proveniente de proteínas, carboidratos e lipídios, foi, respectivamente, de $15,5,54,4$ e $30,1 \%$, para as mulheres, e de 15,5, 54,9 e 29,6\%, para os homens.

Outro resultado a ser destacado diz respeito ao incremento do teor de lipídios conforme há aumento da renda. Análises anteriores implementadas por Bleil $^{[18]} \mathrm{e}$ Faganello ${ }^{[20]}$ identificaram tendência similar. Estes autores analisaram dados da população brasileira, obtidos em meados da década de 90, e destacaram que a renda exerce influência positiva na disponibilidade lipídica, no âmbito dos domicílios, das famílias residentes nas regiões metropolitanas de Curitiba, Porto Alegre, Recife e São Paulo, focos centrais das referidas pesquisas.

Bonomo et al. ${ }^{[21]}$, com base em estudo realizado no município de Bambuí - MG 
(Região Sudeste), também verificaram que com o aumento da renda familiar, homens e mulheres (cerca de 30\% do total da amostra) apresentaram uma tendência de elevação do consumo de lipídios, ultrapassando o limite (30\% do total de energia) recomendado pela Organização Mundial da Saúde ${ }^{[2]}$.

Especialistas têm chamado a atenção para o crescimento da densidade energética da dieta, em virtude do aumento da proporção de lipídios na energia total disponível ${ }^{[22]}$. Além disso, inúmeras pesquisas identificaram relação positiva entre hábitos alimentares, caracterizados pelo consumo expressivo de gorduras, e o aumento dos níveis de lipídios séricos, que contribuem diretamente para o maior risco de doenças cardiovasculares ${ }^{[23,24]}$.

\section{Disponibilidade de fibras e colesterol}

A análise relativa à disponibilidade de fibras nos domicílios revela dados preocupantes. Tendo por base a referência preconizada, por exemplo, para um adulto (31 g), o exame da Tabela 2 mostra que os valores médios obtidos revelam-se muito aquém do valor estabelecido pelo Institute of Medicine ${ }^{[15]}$. A maior disponibilidade média $(12,1 \mathrm{~g})$ de fibras pode ser verificada entre as famílias com rendimentos entre 20,1 s.m. e 30 s.m., enquanto a menor $(8,8 \mathrm{~g})$ foi encontrada para o grupamento com rendimentos entre 10,1 s.m. e 15,0 s.m.

Lima et al. ${ }^{[25]}$, ao investigarem a dieta habitual de crianças e adolescentes com sobrepeso e obesidade, verificaram baixa ingestão de fibras na totalidade dos grupos pesquisados. Os referidos autores verificaram ainda uma correlação negativa entre o índice de massa corporal e o consumo de fibra alimentar entre o grupo de indivíduos obesos do gênero feminino.

Ainda de acordo com a Tabela 2, os dados relativos ao colesterol mostram que a maior disponibilidade $(96 \mathrm{mg}$ ) foi observada entre as famílias relativamente mais ricas. Inversamente, o menor conteúdo do referido nutriente $(49,2 \mathrm{mg})$ foi identificado no grupamento integrado pelos indivíduos mais pobres $(\leq 2$ s.m. $)$.

Tabela 2. Disponibilidade domiciliar diária de fibra e colesterol para as famílias moradoras da Região Centro-Oeste do Brasil, de acordo com os estratos de rendimentos mensais. 2002-2003.

\begin{tabular}{ccc}
\hline Estratos de Rendimentos & \multicolumn{2}{c}{ Nutrientes } \\
\cline { 2 - 3 } (em salários mínimos) & Fibras $(\mathrm{g})$ & Colesterol $(\mathrm{mg})$ \\
\hline 2,0 & 10,3 & 49,2 \\
2,1 a 3,0 & 10,9 & 59,1 \\
3,1 a 5,0 & 9,6 & 61,1 \\
5,1 a 6,0 & 10,6 & 73,8 \\
6,1 a 8,0 & 11,2 & 90,3 \\
8,1 a 10,0 & 10,6 & 73,6 \\
10,1 a 15,0 & 8,8 & 68,4 \\
15,1 a 20,0 & 8,9 & 64,0 \\
20,1 a 30,0 & 12,1 & 60,5 \\
> 30,1 & 10,1 & 96,0 \\
\hline
\end{tabular}


É interessante notar ainda que, embora a disponibilidade de colesterol tenda a aumentar com os rendimentos, o limite máximo de 300 $\mathrm{mg} /$ dia, preconizado pela Organização Mundial de Saúde ${ }^{[2]}$, não foi observado entre as famílias pesquisadas.

Quanto à ingestão de colesterol, Fietz ${ }^{[19]}$ identificou valores médios que se revelaram muito superiores aos valores recomendados e, no que diz respeito às fibras, valores muito reduzidos para ambos os gêneros.

Dessa maneira, os resultados referentes à disponibilidade de colesterol mostraram-se satisfatórios, especialmente se forem considerados os prejuízos ocasionados à saúde em decorrência do consumo excessivo deste nutriente. Entretanto, cumpre salientar que a análises elaboradas nesta pesquisa envolveram somente a disponibilidade (média) de alimentos no domicílio e, portanto, os resultados devem ser observados cuidadosamente, tendo a possibilidade de serem subestimados.

\section{Participação dos grupos alimentares no VET}

Tendo em vista a importância do conhecimento da contribuição dos diversos grupos de alimentos para o VET disponível para as famílias, foi elaborada a Tabela 3, onde foram reunidos os resultados $\mathrm{e}$ classificados de acordo com o estrato geográfico (rural ou urbano) do domicílio.

As informações da Tabela 3 mostram que os alimentos de origem vegetal, reconhecidos como básicos para a alimentação (cereais e derivados, raízes e tubérculos), correspondem a cerca de $40 \%$ da energia total disponível para as famílias moradoras em ambos os estratos geográficos.

A participação na dieta do grupo dos cereais e derivados e raízes e tubérculos mostrou-se semelhante nas áreas urbanas e rurais, sendo discretamente superior para as famílias residentes no meio rural.
Ressalta-se que a evolução da disponibilidade domiciliar de alimentos, obtida por meio de inquéritos populacionais, implementados pelo Instituto Brasileiro de Geografia e Estatística, evidencia uma redução expressiva do consumo das raízes e tubérculos nas últimas três décadas ${ }^{[26]}$.

A contribuição energética proveniente das carnes e embutidos revelou-se superior (33\% maior) para as famílias das áreas urbanas.

Pesquisa de Fietz ${ }^{[19]}$, tendo por base moradores de área rural, identificou que os cereais forneceram a maior parcela de energia para o VET, quando comparados às demais fontes de carboidratos. As carnes e os embutidos foram identificados como as principais fontes de proteína e lipídios. A participação da banha de porco e do toucinho na dieta dos participantes foi superior aos valores médios identificados por meio das pesquisas nacionais.

No que se refere ao grupo das leguminosas, sua contribuição para a alimentação das famílias da Região CentroOeste mostrou-se semelhante em ambos os estratos geográficos: $5,5 \%$ no meio rural e $5,4 \%$ no meio urbano.

A análise dos resultados obtidos por meio de inquéritos domiciliares, referente ao período de $1974-75$ e 2002-2003, revela que alimentos tradicionais na dieta da população brasileira, como é o caso do feijão, perderam "espaço" nas últimas três décadas. Essa redução da participação do grupo das leguminosas, identificada nesse período, devese, sobretudo, à diminuição do consumo de feijão, que apresentou um declínio de $30 \%{ }^{[26]}$.

Os resultados revelaram que a participação do grupo do leite e derivados na alimentação mostrou-se maior para as famílias residentes nas áreas rurais $(8,8 \%)$, ocasionada, talvez, pela expressiva contribuição em especial do leite, considerado um alimento acessível pela população rural, principalmente pelas maiores possibilidades de auto-produção nessa região do país. 
Tabela 3. Participação relativa dos grupos de alimentos no VET diário disponível para as famílias da Região Centro-Oeste do Brasil, de acordo com o estrato geográfico (rural ou urbano), 2002/2003.

\begin{tabular}{|c|c|c|c|c|c|c|}
\hline \multirow{3}{*}{ Grupos de alimentos } & \multicolumn{6}{|c|}{ Valor Energético Total - VET e contribuição dos grupos de alimentos } \\
\hline & \multirow[b]{2}{*}{$\begin{array}{c}\text { Energia } \\
(\mathrm{kcal})\end{array}$} & \multirow[b]{2}{*}{$\%$} & \multicolumn{2}{|c|}{ Rural } & \multicolumn{2}{|c|}{ Urbano } \\
\hline & & & $\begin{array}{c}\text { Energia } \\
\text { (kcal) }\end{array}$ & $\%$ & $\begin{array}{c}\text { Energia } \\
\text { (kcal) }\end{array}$ & $\%$ \\
\hline Cereais e derivados & 651,7 & 38,9 & 981,4 & 39,0 & 606,3 & 38,8 \\
\hline $\begin{array}{l}\text { Raízes, tubérculos e } \\
\text { derivados }\end{array}$ & 37,1 & 2,2 & 74,4 & 2,9 & 31,9 & 2,1 \\
\hline Carnes e embutidos & 161,8 & 9,7 & 190,0 & 7,6 & 157,9 & 10,1 \\
\hline Leguminosas & 90,3 & 5,4 & 138,2 & 5,5 & 83,7 & 5,4 \\
\hline Leite e derivados & 100,9 & 6,0 & 221,4 & 8,8 & 84,3 & 5,4 \\
\hline Ovos & 8,4 & 0,5 & 17,8 & 0,7 & 7,2 & 0,5 \\
\hline Hortaliças & 6,7 & 0,4 & 8,3 & 0,3 & 6,5 & 0,4 \\
\hline Frutas & 18,7 & 1,1 & 14,5 & 0,6 & 19,3 & 1,2 \\
\hline Açúcares e doces & 235,5 & 14,0 & 363,2 & 14,4 & 217,9 & 13,9 \\
\hline $\begin{array}{l}\text { Óleos e gorduras } \\
\text { vegetais }\end{array}$ & 296,8 & 17,1 & 416,8 & 16,6 & 268,8 & 17,2 \\
\hline $\begin{array}{l}\text { Banha, toucinho, } \\
\text { maionese e creme de } \\
\text { leite }\end{array}$ & 27,3 & 1,6 & 48,5 & 1,9 & 24,4 & 1,6 \\
\hline Oleaginosas & 0,1 & 0,0 & 0,2 & 0,0 & 0,1 & 0,0 \\
\hline Refrigerantes & 18,8 & 1,1 & 12,8 & 0,5 & 19,6 & 1,3 \\
\hline $\begin{array}{l}\text { Bebidas não- } \\
\text { alcoólicas }\end{array}$ & 6,3 & 0,4 & 7,2 & 0,3 & 6,1 & 0,4 \\
\hline Bebidas alcoólicas & 8,2 & 0,5 & 8,1 & 0,3 & 8,2 & 0,5 \\
\hline $\begin{array}{l}\text { Preparações prontas } \\
\text { para consumo }\end{array}$ & 14,0 & 0,8 & 7,4 & 0,3 & 14,9 & 1,0 \\
\hline Condimentos & 4,6 & 0,3 & 6,1 & 0,2 & 4,4 & 0,3 \\
\hline Total & 1677,0 & 100,0 & 2516,1 & 100,0 & 1561,5 & 100,0 \\
\hline
\end{tabular}

Cabe mencionar que Fietz ${ }^{[19]}$ concluiu que o grupo do leite e derivados representou a principal fonte de cálcio da população assentada de sua pesquisa. $\mathrm{O}$ autor observou, também, que cerca de $50 \%$ do ferro consumido, por ambos os gêneros, foi proveniente dos cereais.

A participação na dieta de frutas e hortaliças revelou variação entre $0,9 \%$ e $1,6 \%$, para as famílias dos estratos rural e urbano, respectivamente. É importante ressaltar que a participação desse grupo no VET é cerca de três vezes menor que os valores preconizados pela $\mathrm{WHO}^{[2]}$ para o consumo desses alimentos (mínimo de 400 gramas diários ou cerca de 6 a $7 \%$ da energia total, quando for considerada uma dieta de $2.300 \mathrm{kcal}$ diárias). Ressalta-se que os valores recomendados pelo Ministério da Saúde ${ }^{[27]}$, no tocante à ingestão de frutas e hortaliças, divulgados recentemente por meio 
do "Guia Alimentar para a População Brasileira", também prevêem uma ingestão mínima de $400 \mathrm{~g} /$ dia deste grupo de alimentos, perfazendo um total de 9 a $12 \%$ da energia consumida (considerando uma dieta de 2.000 $\mathrm{kcal} / \mathrm{dia})$.

Resultado também preocupante, referente às frutas e verduras, foi apresentado por Fietz ${ }^{[19]}$. A contribuição destes alimentos foi pouco expressiva, sendo as raízes e os tubérculos identificados como principais fontes de vitamina C. Cabe lembrar que a referida pesquisa envolveu moradores de áreas rurais que dispunham de áreas/lotes, com espaços expressivos para a produção desses alimentos para o autoconsumo.

De acordo com a World Health Organization $^{[2]}$, o aumento do consumo de frutas e hortaliças é recomendado, tendo em vista que estes alimentos poderiam substituir outros que possuem elevado conteúdo energético e reduzido valor nutritivo, como cereais e grãos processados e açúcar refinado, muito comuns na preparação de alimentos industrializados e fast-food.

Diversos estudos têm evidenciado que o consumo de frutas e hortaliças pode estar inversamente associado ao risco de diabetes melito tipo 2, de doenças cardiovasculares, alguns tipos de câncer, além de sua possível contribuição no balanço energético ${ }^{[28,29]}$.

Hábitos alimentares saudáveis, como a ingestão adequada de frutas e hortaliças, têm sido apontados como protetores no desenvolvimento da obesidade. Este efeito deve-se à menor densidade energética e ao conteúdo elevado de fibras que se mostra associado ao aumento da saciedade ${ }^{[2]}$.

Os resultados referentes à participação relativa no VET dos açúcares, doces e dos refrigerantes, caracterizados como carboidratos simples, revelaram uma disponibilidade (média) excessiva tanto para as famílias residentes nas áreas rurais $(14,9 \%)$ quanto urbanas $(15,2 \%)$ do Centro-Oeste brasileiro.

É possível observar que a participação do referido grupo de alimentos no VET disponível nos domicílios supera o limite máximo de $10 \%$, preconizado pelas recomendações nutricionais ${ }^{[2]}$.
Especificamente aos refrigerantes, Tomita e Cardoso $^{[30]}$ identificaram, ao analisar sua contribuição no VET diário da população adulta no município de São Paulo, uma participação mais expressiva deste tipo de produto $(2,5 \%)$ na energia disponível, comparada àquela encontrada nesta pesquisa.

Vale lembrar que os resultados obtidos no presente trabalho referem-se, exclusivamente, à disponibilidade de alimentos no âmbito doméstico. Dessa maneira, é possível que a participação relativa desse grupo de alimentos, especialmente quando são considerados os refrigerantes, supere os valores identificados, tendo em vista a contribuição das refeições realizadas fora do domicílio, incluindo lanches rápidos acompanhados, freqüentemente, por refrigerantes e muito apreciados pelas crianças e adolescentes.

A participação dos alimentos muito calóricos (óleos e gorduras vegetais) na alimentação revelou-se (em média) ligeiramente maior nas áreas urbanas $(17,2 \%)$, quando comparada ao valor obtido para as famílias das áreas rurais $(16,6 \%)$. Dados de inquéritos domiciliares implementados pelo IBGE, nas décadas de 70, 80, 90 e, o mais recente, realizado entre os anos de 2002-2003, evidenciam que a participação das gorduras na alimentação tem aumentado substancialmente ao longo dos anos. Estas mesmas análises também revelam que, de uma maneira geral, a proporção de energia originária de gorduras excedeu (tendo por base a última pesquisa) o limite máximo de $30 \%$ recomendado pela Organização Mundial de Saúde ${ }^{[2]}$. Estes resultados despertam certa preocupação, pois pesquisas atuais têm revelado forte correlação entre a incidência de doenças ateroscleróticas, níveis de lipídios séricos e hábitos alimentares $^{[31]}$.

Cumpre salientar também que a quantidade e a natureza da gordura da dieta interferem nos níveis de colesterol plasmático e que os elevados conteúdos de colesterol sanguíneo são fortemente relacionados à doença vascular aterosclerótica, sobretudo à doença coronariana ${ }^{[32]}$.

Alimentos como banha, toucinho, maionese e creme de leite estiveram mais 
presentes na alimentação das famílias residentes no meio rural. Este resultado não frustrou as expectativas, observando-se o tradicional hábito, por exemplo, do uso da banha de porco no preparo de alimentos entre as famílias das áreas rurais.

É interessante destacar que os referidos alimentos são compostos, predominantemente, por ácidos graxos saturados, reconhecidos por seu importante efeito hipercolesterolêmico (elevação das lipoproteínas de baixa densidade e redução das lipoproteínas de alta densidade). No entanto, ressalta-se que a energia proveniente desse grupo de alimentos revelou-se inferior ao limite máximo aceitável para as gorduras saturadas (10\% das calorias totais) para a amostra de famílias dos dois estratos geográficos considerados.

Mondini e Monteiro ${ }^{[33]}$ identificaram, ao comparar os resultados referentes a três inquéritos nacionais, realizados entre os anos de 1962 e 1988, uma substituição expressiva de gorduras animais, como banha, toucinho e manteiga, por óleos vegetais e margarinas. Entre 1988 e 1996, Monteiro et al. ${ }^{[33]}$ verificaram também que a participação das gorduras, provenientes de fontes animais na dieta, manteve-se reduzida, representando cerca de $1 \%$ do total energético.

Outro resultado que merece destaque é a presença das preparações prontas para o consumo como item da alimentação da população. Também de acordo com a Tabela 3 , verifica-se que a contribuição energética oriunda desse grupo para as famílias do meio urbano $(1,0 \%)$ corresponde ao triplo daquela observada nas áreas rurais $(0,3 \%)$.

Alguns dados apresentados por Garcia $^{[34]}$ mostram que a produção de alimentos congelados, considerados produtos de maior praticidade e que facilitam o trabalho doméstico, cresceu cerca de $130 \%$ entre os anos de 1990 e 1996. Outro alimento que apresentou um aumento expressivo (considerando um período de cerca de 15 anos) em sua produção foi o salgadinho industrializado, passando de 20 mil toneladas em 1980, para 124 mil toneladas em 1996.

Os dados referentes à evolução da contribuição das refeições prontas para o consumo e misturas industrializadas para a energia disponível evidenciam uma tendência de ampliação desse grupo na alimentação dos brasileiros, nas últimas três décadas, especialmente quando são considerados os centros urbanos. Em 1975, a contribuição desses alimentos para o conteúdo total de energia representava $1,26 \%$, ao passo que em 2003, essa participação alcançou 2,29\%, representando um incremento de cerca de $80 \%$.

\section{Conclusão}

Embora os dados relativos ao consumo alimentar, obtidos pelas pesquisas de orçamentos familiares, não possibilitem a aferição da quantidade absoluta de alimentos ingeridos pelos membros das famílias, eles constituem uma fonte alternativa interessante de informações sobre disponibilidade de alimentos. Além disso, as POF's permitem o estudo de grupos específicos da população por disponibilizarem informações para distintos estratos socioeconômicos e geográficos.

É importante salientar ainda que os resultados da presente pesquisa podem estar subestimados pelo fato de não levarem em consideração a ingestão individual de alimentos, bem como o consumo de alimentos fora do domicílio.

Os resultados mostram que o padrão de alimentação da população brasileira (notadamente quando são considerados os moradores da região Centro-Oeste) tem exibido expressivas mudanças, que merecem atenção, tendo em vista os graves problemas decorrentes do consumo inadequado de alimentos.

Intervenções devem ser adotadas de imediato, especialmente aquelas voltadas para o incentivo do consumo de frutas e hortaliças e redução do consumo de açúcares, doces e refrigerantes. Vale lembrar que as ações direcionadas para a mudança de hábitos alimentares devem envolver, prioritariamente, atividades relativas à educação para o consumo e políticas públicas de segurança alimentar e nutricional, notadamente aquelas que envolvam estímulos e/ou subsídios para a aquisição de alimentos saudáveis. 


\section{Agradecimentos}

As autoras agradecem a valiosa colaboração de Marcelo Correa Alves (Ciagri - Esalq USP), com as análises dos dados individuais.

\section{Referências Bibliográficas}

1. Bermudez OI, Tucker KL. Trends in dietary patterns of Latin American populations. Cad Saúde Pública. 2003;19 (Supl 1):87-99.

2. World Health Organization (OMS). Diet, nutrition and the prevention of chronic diseases. Geneva; 2003. 160 p. (WHO. Technical Report Series, $\mathrm{n}^{\circ}$ 916).

3. Mendonça CP, Anjos LA. Aspectos das práticas alimentares e da atividade física como determinantes do crescimento do sobrepeso/obesidade no Brasil. Cad Saúde Pública. 2004; 20(3):698-709.

4. Barreto SAJ, Cyrillo DC. Análise da composição dos gastos com alimentação no Município de São Paulo (Brasil) na década de 1990. Rev Saúde Pública. 2001; 35(1):52-9.

5. Claro RM. Influência da renda e preço dos alimentos sobre a participação de frutas, legumes e verduras no consumo alimentar das famílias do município de São Paulo. [dissertação]. São Paulo: Faculdade de Saúde Pública; 2006. 96 p.

6. Darmon N, Ferguson E, Briend A. Do economic constraint encourage the selection of energy dense diets? Appetite. 2003; 41:31522.

7. Haddad L. What can food policy do to redirect diet transition? Washington; 2003 (FCND Discussion Paper $\mathrm{n}^{\mathrm{o}}$ 165).

8. Instituto Brasileiro de Geografia e Estatística (IBGE). Pesquisa de orçamentos familiares 2002/2003: microdados - segunda divulgação. Rio de Janeiro, 2005.

9. Ornellas LH. Técnica dietética: seleção e preparo de alimentos. $7^{\mathrm{a}}$.ed. São Paulo: Atheneu; 2001.

10. Silva SMCS da; Bernardes SM. Cardápio: guia prático para a elaboração. São Paulo: Atheneu; 2001.

11. Philippi ST, Szarfarc SC, Latterza AR. Virtual nutri: versão 1.0 for windows (software). São Paulo: Universidade de São
Paulo, Faculdade de Saúde Pública, Departamento de Nutrição, 1996.

12. Instituto Brasileiro de Geografia e Estatística (IBGE). Estudo nacional de despesas familiares: tabelas de composição de alimentos. 2. ed. Rio de Janeiro, 1999. 213p.

13. Núcleo de Estudos e Pesquisas em Alimentação. Tabela brasileira de composição de alimentos. Campinas: Flamboyant; 2004.

14. Universidade Federal de São Paulo. Tabela de composição química dos alimentos. [citado em 16 de mar de 2005]. Disponível em: http//www.unifesp.br/dis/sevicos/nutri

15. Institute of Medicine (IOM). Food and Nutrition Board, Standing Committee on the Scientific Evaluation of Dietary Reference Intakes. Dietary reference intakes for energy, carbohydrate, fiber, fat, fatty acids, cholesterol, protein and amino acids. Washington, D.C., National Academy Press; 2002.

16. Food and Agriculture Organization (FAO). Nutrition country profiles: Brasil. Rome, 2000. [citado em 19 ago 2005]. Disponível em: http://www.fao.org/es/ESN/nutrition/brae.stm.

17. Silveira FG, Magalhães LCG, Tomich FA, Vianna STW, Safatle L, Leal JC. Insuficiência alimentar nas grandes regiões urbanas brasileiras. Brasília: IPEA, 2002. (Texto para Discussão $n^{\circ} 884$ ).

18. Bleil RAT. Disponibilidade de energia e nutrientes nos domicílios de famílias das regiões metropolitanas de Curitiba e Porto Alegre. [dissertação]. Piracicaba: Escola Superior de Agricultura "Luiz de Queiroz"; 2004. $87 \mathrm{p}$.

19. Fietz VR. Estado nutricional, consumo de alimentos e condições socioeconômicas das famílias de assentamento rural em Mato Grosso do Sul, Brasil. [tese]. Campinas: Faculdade de Engenharia de Alimentos da Universidade Estadual de Campinas, 2007. $157 \mathrm{p}$. 
20. Faganello CRF. Disponibilidade de energia e nutrientes para a população das regiões metropolitanas de Recife e São Paulo. [dissertação]. Piracicaba: Escola Superior de Agricultura "Luiz de Queiroz"; 2002. 113 p.

21. Bonomo E, Caiaffa WT, César CC, Lopes ACS, Lima-Costa MF. Consumo alimentar da população adulta segundo perfil socioeconômico e demográfico: Projeto Bambuí. Cad Saúde Pública. 2003; 19(5):1461-71.

22. Mondini L, Monteiro CA. Mudanças no padrão de alimentação da população urbana brasileira (1962-1988). Rev Saúde Pública. 1994; 28(6):433-9.

23. Fornés NS, Martins IS, VelásquezMeléndez G, Latorre MRDO. Escores de consumo alimentar e níveis lipêmicos em população de São Paulo, Brasil. Rev Saúde Pública. 2002; 36(1):12-8.

24. Oliveira MC de, Sichieri R. Fracionamento das refeições e colesterol sérico em mulheres com dieta adicionada de frutas ou fibras. Rev Nutr. 2004; 17(4):44959.

25. Lima SCV, Arrais RF, Pedrosa LFC. Avaliação da dieta habitual de crianças e adolescentes com sobrepeso e obesidade. Rev Nutr. 2004; 17(4):469-77.

26. Instituto Brasileiro de Geografia e Estatística (IBGE). Pesquisa de orçamentos familiares 2002/2003: análise da disponibilidade domiciliar de alimentos e do estado nutricional no Brasil. Rio de Janeiro, 2004.

27. BRASIL. Ministério da Saúde. Atenção integrada às doenças prevalentes na infância. [citado em 10 ago 2005]. Disponível em:

http//www.saude.gov.br/programas/scriança/cr iança/aidpi/aidpi1.htm

28. Chen H, Ward MH, Graubard BH, Heineman EF, Markin RM, Potischman NA, Russel RM, Weisenburger DD, Tucker KL. Dietary patterns and adenocarcinoma of the esophagus and distal stomach. Am J Clin Nutr. 2002; 75(1):137-44.

29. Ford ES, Mokdad AH. Fruit and vegetable consumption and diabetes mellitus incidence among US adults. Prev Medicine. 2001; 32(1):33-9.

30. Tomita LY, Cardoso MA. Avaliação da lista de alimentos e porções alimentares de questionário quantitativo de freqüência alimentar em população adulta. Cad Saúde Pública. 2002; 18(6):1747-56.

31. Haile RWC. Identifying a limited number of foods important in supplying selected dietary nutrients. J Am Dietetic Assoc. 1998; 86:611-16.

32. Fornés NS, Martins IS, Hernan M, Velásquez-Meléndez G, Ascherio A. Food frequency consumption and lipoproteins serum levels in the population of an urban area, Brazil. Rev Saúde Pública. 2000; 34(4):380-7.

33. Monteiro CA, Mondini L, Costa RBL. Mudança na composição e adequação nutricional da dieta familiar nas áreas metropolitanas do Brasil (1988-1996). Rev Saúde Pública. 2000; 34(3):251-8.

34. Garcia RWD. Reflexos da globalização na cultura alimentar: considerações sobre as mudanças na alimentação urbana. Rev Nutr. 2003; 10(4):483-92.

\section{Autores}

Carla Cristina Enes - Doutoranda do Departamento de Nutrição da Faculdade de Saúde Pública da USP.

Correspondência: Rua Capitão Alfredo Cardoso, 54 bairro Jardim Faculdade.

Sorocaba - SP CEP 18030-310. - E-mail: cenes@usp.br

Marina Vieira da Silva - Professora Doutora do Departamento de Agroindústria, Alimentos e Nutrição da Escola Superior de Agricultura "Luiz de Queiroz" ESALQ/USP.

Recebido em: 17/03/2008

Aceito em: 23/06/2008 